\title{
Tuberculosis among migrant workers in Taiwan
}

\author{
Chia-Wen Lu' ${ }^{1,2}$, Yi-Hsuan Lee ${ }^{3}$, Yu-Hao Pan ${ }^{1}$, Hao-Hsiang Chang ${ }^{1}$, Yi-Chun Wu ${ }^{4}$, Wang-Huei Sheng ${ }^{5}$ and \\ Kuo-Chin Huang ${ }^{1,3^{*}}$ (D)
}

\begin{abstract}
Background: Although the worldwide incidence of tuberculosis (TB) has been slowly decreasing, the migrant workers remains an important gap for regional TB control. In Taiwan, the numbers of the migrant workers from countries with high TB incidence increase significantly in past decades and the impact on public health remains unknown. This study aimed to explore the difference of TB incidence between Taiwanese and the migrant workers.

Methods: The migrant workers are obligated to receive pre-arrival, post-arrival and regular chest X-ray screening during their stay in Taiwan. We retrospectively collected these data extracted from the Alien Workers Health Database in Centers for Disease Control, Taiwan from Jan. 1, 2004 to Dec. 31, 2013. Poisson regression models were used to compare the hazard ratios of TB between Taiwanese and the migrant workers after adjusting gender and age groups.

Results: The total migrant workers in Taiwan reached 314,034 persons in 2004 and 489,134 persons in 2013, accounting for $2 \%$ of Taiwan population. The TB incidence of migrant workers was similar to Taiwanese (53-73.7 per $10^{5}$ vs $45.5-76.8$ per $10^{5}$ ). Comparing with Taiwanese, the TB risk was significantly lower in male migrant workers (HR: 0.76; 95\% Cl: 0.70-0.83, $P<0.001$ ), but higher in female migrant workers (HR: 1.40; 95\% Cl: 1.35-1.46, $P<0.001$ ). Besides, we found that the TB risk in migrant workers was 5.30 -fold ( $95 \% \mathrm{Cl}$ : 4.83-5.83, $P<0.001$ ) in youngest group ( $\leq 24$ yearold) comparing with Taiwanese.
\end{abstract}

Conclusions: Migrant workers in Taiwan have higher TB incidence than Taiwanese in young groups, especially in females. The mainstay young laborers with latent tuberculosis infection risk is an important vulnerability for public health. Further investigation and health screening are warranted.

Keywords: Tuberculosis, Migrant workers, Latent tuberculosis infection, Foreigner workers

\section{Background}

Tuberculosis (TB) is the ninth leading cause of death worldwide, with most of them could be prevented with early diagnosis and appropriate treatment [1]. In 2016, there were 6.3 million new cases of TB globally [1]. Among the new cases, the top two incidence countries were India and Indonesia and the most TB-resistant countries were India and China [1]. Similarly, TB is one of the top infectious diseases and an important public health concern in Taiwan. The Bureau of National

\footnotetext{
* Correspondence: bretthuang@ntu.edu.tw

${ }^{1}$ Department of Family Medicine, National Taiwan University Hospital, Taipei, Taiwan

${ }^{3}$ Department of Family Medicine, National Taiwan University Hospital Bei-Hu Branch, Taipei, Taiwan

Full list of author information is available at the end of the article
}

Health Insurance (NHI) in Taiwan introduced the no-notification-no-reimbursement policy to enhance TB notification and to decrease the incidence of $\mathrm{TB}$ since 1997 [2]. Accordingly, the NHI, which enrolled up to 99\% of Taiwanese, has reached the TB notification rate more than 97\% since 2007 [3, 4]. Also, the TB numbers (incidence) in Taiwan dropped from more than 16,000 cases (72 cases per $10^{5}$ persons) in 2005 to less than 10,000 cases ( 41 cases per $10^{5}$ persons) in 2017 [5].

Previous studies have shown that migrant workers from countries with a high incidence of TB have a significant impact on the epidemic of TB in low-incidence countries [6-8]. Pre-entry screening programs for tuberculosis in migrant workers is believed to be a high yield policy for active $\mathrm{TB}$ [9], though the risk of latent $\mathrm{TB}$

(C) The Author(s). 2019 Open Access This article is distributed under the terms of the Creative Commons Attribution 4.0 International License (http://creativecommons.org/licenses/by/4.0/), which permits unrestricted use, distribution, and 
reactivation is persistent $[10,11]$. The average annual TB notification rate is reported to be higher in the foreign-born population than the Taiwan-born population [12]. In addition, the numbers of the migrant workers in Taiwan from countries with high TB incidence increase significantly in past decades [5]. Although the migrant workers have to receive pre-entry screening and post-arrival regular health check-up, to date, little is known about the $\mathrm{TB}$ incidence and the characteristics of TB population of the migrant workers in Taiwan. Therefore, this study aimed to explore the difference of TB incidence between Taiwanese and migrant workers. Also, the study aimed to compare the gender and age differences of TB burden in Taiwanese with the migrant workers.

\section{Methods}

\section{Design}

The profile of the general population of Taiwanese was obtained from the official publications of the Ministry of the Interior, Taiwan [13]. The incidence rate of TB detected in each origin countries were estimated by the WHO [14]. The profile of migrant workers was extracted from the National Immigration Agency where the number of persons entering and leaving Taiwan were recorded and stratified by country of origin, gender and age [15]. Since TB is a notifiable disease by the Law on the Control of Communicable Diseases in Taiwan, data of all TB cases in Taiwanese notified between January 1, 2004 and December 31, 2013 were obtained from the National TB Registry [16]. All migrant workers were obligated to receive pre-arrival, post-arrival (within 3 days after arrival) and regular chest X-ray screening (6th, 18th and 30th month after arrival) during their stay in Taiwan [17]. Besides, all migrant workers were seronegative of human immunodeficiency virus (HIV) before their entry and were excluded from the study once diagnosis of HIV infection. Also, we retrospectively collected TB cases from Alien Workers Health Database in Centers for Disease Control, Taiwan [18]. The epidemiological records in their native-born countries were extracted from annual reports in World Health Organization [19]. The design of the study was approved by the Research Ethics Committee in National Taiwan University Hospital (201807018W) before the study was conducted.

\section{Case definition}

TB in Taiwan was diagnosed by two approaches: 1) laboratory diagnosis: human specimens which was smearpositive for acid-fast bacilli and/or culture-positive for Mycobacterium tuberculosis including sputum, body fluid and tissue; 2) clinical diagnosis by specialists: the clinical and radiographic manifestations were compatible with TB, the patient was received detailed evaluation to exclude other diagnoses, and the patient has initiated treatment with more than one anti-tuberculosis drugs [19].

\section{Statistical analysis}

The baseline categorical data were presented by frequency with percentages. The TB incidence was defined as the number of events divided by the follow-up person-years, which were calculated as the time from 2004 to the diagnosis of TB, death or the end of 2013. We used Poisson regression models to assess hazard ratios (HRs) and 95\% confidence intervals (CIs) of TB for the Taiwanese compared to the migrant workers after adjusting gender and age groups respectively. All 2-sided $p$ values were presented. All analyses were computed using the SAS version 9.4 (SAS Institute Inc. Cary, North Carolina).

\section{Results}

The total migrant workers in Taiwan reached 314,034 persons in 2004 and 489,134 persons in 2013, accounted for $2 \%$ of Taiwan population. The mainly import countries were Indonesia, Philippines, Thailand, and Vietnam in Fig. 1. From 2004 through 2013, 2256 new cases of TB were found among migrant workers during their regular health examination in Tables 1 and 2. The TB incidence of the migrant workers was similar to Taiwanese. (53-73.7 per $10^{5}$ vs $45.5-76.8$ per $10^{5}$ ) From 2004 to 2013, the annual TB incidence in Taiwanese has been decreasing whereas the annual TB incidence in migrant workers has been increasing in Fig. 2. Therefore, the TB incidence of migrant workers exceeded Taiwanese since 2012.

Comparison of TB incidence among migrant workers and Taiwanese by different countries and genders are shown in Table 3. Comparing with Taiwanese by different countries, the TB risk was significantly higher in Philippines (HR: 1.22; 95\%CI: 1.15-1.30, $P<0.001$ ) but lower in Vietnamese (HR: 0.57; 95\%CI: 0.47-68, $P<$ 0.001). Comparing with Taiwanese by different genders, the TB risk was significantly lower in male migrant workers (HR: 0.76; 95\% CI: 0.70-0.83, $P<0.001$ ), but higher in female migrant workers (HR: 1.40; 95\% CI: 1.35-1.46, $P<0.001)$.

The TB risk was highest in 45-54 year-old group (49.6 per $\left.10^{5}\right)$ and lowest in $\leq 24$ year-old group $\left(12.4\right.$ per $\left.10^{5}\right)$ in Taiwanese while the TB risk was highest in 25-34 year-old group $\left(65.9\right.$ per $\left.10^{5}\right)$ but lowest in $45-54$ year-old group (30.8 per $10^{5}$ ) in migrant workers in Table 4 . Applying Poisson regression models to test the differences among Taiwanese and migrant workers in each age group, we found that the TB risk in migrant workers was 5.30-fold in $\leq 24$ year-old group comparing with Taiwanese (95\%CI: 4.83-5.83, $P<0.001)$. Compared with Taiwanese, the TB risk of migrant workers in 25-34 year 


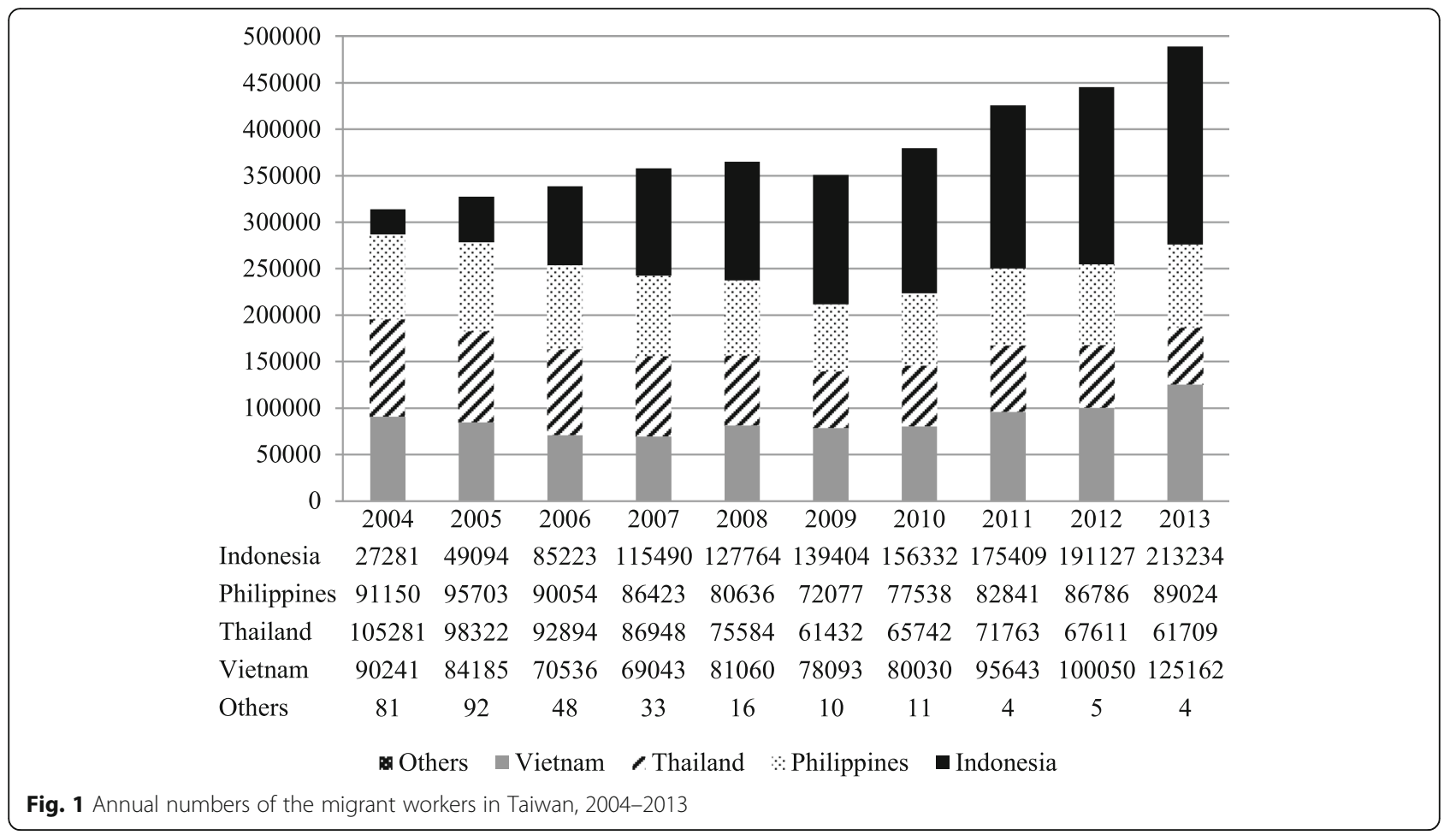

old and 35-44 year old groups are 2.63 fold (95\%CI: 2.49-2.79, $P<0.001)$ and 1.40 fold (95\%CI: $1.27-1.54$, $P<0.001)$ respectively.

\section{Discussion}

To our knowledge, this is the first study to explore the TB incidence of the migrant workers in Taiwan. The nationwide, long-term follow-up, retrospective cohort study investigated the absolute risk and relative risk of

Table 1 The incidence of tuberculosis among Taiwanese and the foreign laborers during 2004-2013

\begin{tabular}{|c|c|c|c|c|c|c|}
\hline & \multicolumn{3}{|l|}{ Taiwan } & \multicolumn{3}{|c|}{ All foreign laborers } \\
\hline & Case & Population & Incidence $^{a}$ & Case & Population & $\overline{\text { Incidence }}$ \\
\hline 2004 & 16716 & 22689122 & 73.7 & 143 & 314034 & 45.5 \\
\hline 2005 & 16472 & 22770383 & 72.5 & 168 & 327396 & 51.3 \\
\hline 2006 & 15378 & 22876527 & 67.4 & 188 & 338755 & 55.5 \\
\hline 2007 & 14480 & 22958360 & 63.2 & 190 & 357937 & 53.1 \\
\hline 2008 & 14265 & 22037031 & 62 & 239 & 365060 & 65.5 \\
\hline 2009 & 13336 & 23119772 & 57.8 & 193 & 351016 & 55.0 \\
\hline 2010 & 13237 & 23162123 & 57.2 & 196 & 379653 & 51.6 \\
\hline 2011 & 12634 & 23224912 & 54.5 & 257 & 425660 & 60.4 \\
\hline 2012 & 12338 & 23315822 & 53 & 342 & 445579 & 76.8 \\
\hline 2013 & 11528 & 23375517 & 49.4 & 340 & 489133 & 69.5 \\
\hline Average $^{b}$ & - & - & - & - & 379422 & - \\
\hline
\end{tabular}

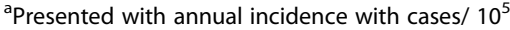

${ }^{\mathrm{b}}$ The annual average numbers of the immigrant workers
$\mathrm{TB}$ in Taiwanese and the migrant workers. Gated by pre-screening program, the TB incidence in migrant workers was similar to Taiwanese but much lower than their native countries. Stratified by gender and age, the highest TB incidence group of the migrant workers were young female, especial in the $\leq 24$ year-old group. There were two hypotheses to explain the differences of TB incidence between Taiwanese and migrant workers.

First hypothesis was that we assumed the high TB incidence after arrival of migrant workers was contributed by reactivation of latent TB infection (LTBI) [7, 11, 20]. In previous studies, the migrant workers, the refugees and the immigrants of US and Europe posed a high TB incidence after their arrival because the most important risk factor of reactivation of LTBI was that they were from countries of high tuberculosis burden [6, 21]. Studies suggest that active TB will develop in 5 to $10 \%$ of persons with LTBI during their lifetimes [22]. And, the highest risk period of reactivation among migrant workers was within first year and then during 2 to 4 years after their arrival [23, 24]. Also, the highest and lowest TB incidence of migrant workers in Taiwan were from Philippines and Vietnam while their native countries were at highest and lowest TB burden, respectively. In line with previous studies, our findings implied that there was a parallel risk of reactivation of LTBI based on the TB prevalence of the native countries $[6,7]$. The current screening tool, chest radiography, was sensitive to detect pulmonary active TB but insufficient to catch 
Table 2 The incidence of tuberculosis among Taiwanese and the foreign laborers by different countries during 2004-2013, stratified by countries

\begin{tabular}{|c|c|c|c|c|c|c|c|c|c|c|c|c|}
\hline & \multicolumn{3}{|c|}{ Indonesia laborers } & \multicolumn{3}{|c|}{ Philippines laborers } & \multicolumn{3}{|c|}{ Thailand laborers } & \multicolumn{3}{|c|}{ Vietnam laborers } \\
\hline & Case & Population & Incidence $^{a}$ & Case & Population & $\overline{\text { Incidence }}$ & Case & Population & $\overline{\text { Incidence }}$ & Case & Population & $\overline{\text { Incidence }}$ \\
\hline 2004 & 26 & 27281 & 95.3 & 41 & 91150 & 45.0 & 48 & 105281 & 45.6 & 28 & 90241 & 31.0 \\
\hline 2005 & 19 & 49094 & 38.7 & 75 & 95703 & 78.4 & 51 & 98322 & 51.9 & 23 & 84185 & 27.3 \\
\hline 2006 & 31 & 85223 & 36.4 & 72 & 90054 & 80.0 & 54 & 92894 & 58.1 & 31 & 70536 & 43.9 \\
\hline 2007 & 56 & 115490 & 48.5 & 61 & 86423 & 70.6 & 41 & 86948 & 47.2 & 32 & 69043 & 46.3 \\
\hline 2008 & 74 & 127764 & 57.9 & 68 & 80636 & 84.3 & 62 & 75584 & 82.0 & 35 & 81060 & 43.2 \\
\hline 2009 & 77 & 139404 & 55.2 & 48 & 72077 & 66.6 & 34 & 61432 & 55.3 & 34 & 78093 & 43.5 \\
\hline 2010 & 77 & 156332 & 49.3 & 56 & 77538 & 72.2 & 33 & 65742 & 50.2 & 30 & 80030 & 37.5 \\
\hline 2011 & 111 & 175409 & 63.3 & 80 & 82841 & 96.6 & 37 & 71763 & 51.6 & 29 & 95643 & 30.3 \\
\hline 2012 & 163 & 191127 & 85.3 & 75 & 86786 & 86.4 & 55 & 67611 & 81.3 & 49 & 100050 & 49.0 \\
\hline 2013 & 152 & 213234 & 71.3 & 75 & 89024 & 84.2 & 55 & 61709 & 89.1 & 57 & 125162 & 45.5 \\
\hline Average $^{b}$ & - & 128036 & - & - & 85223 & - & - & 78729 & - & - & 87404 & - \\
\hline
\end{tabular}

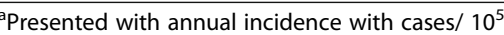

${ }^{\mathrm{b}}$ The annual average numbers of the immigrant workers

LTBI $[1,25]$. Our study pointed out that there was still high TB incidence among migrant workers after their arrival within 30 months. It implied that the current routine chest radiography in migrant workers in Taiwan was for screening pulmonary reactivation of LTBI but not adequate for detecting LTBI [12].

The second hypothesis of the high TB incidence after arrival of migrant workers was due to a new TB infection in Taiwan. Inconsistent with previous findings, which LTBI was more in male and elderly [21, 26], our study revealed that there was more TB cases in female and young group. There are three types of migrant workers in Taiwan: (1) those who work for companies and factories are classified as industrial and business workers, (2) those who work at house unit for cooking, clothing and child raising are classified as household workers, and (3) those who work in health care facilities or respiratory care centers are classified as health care

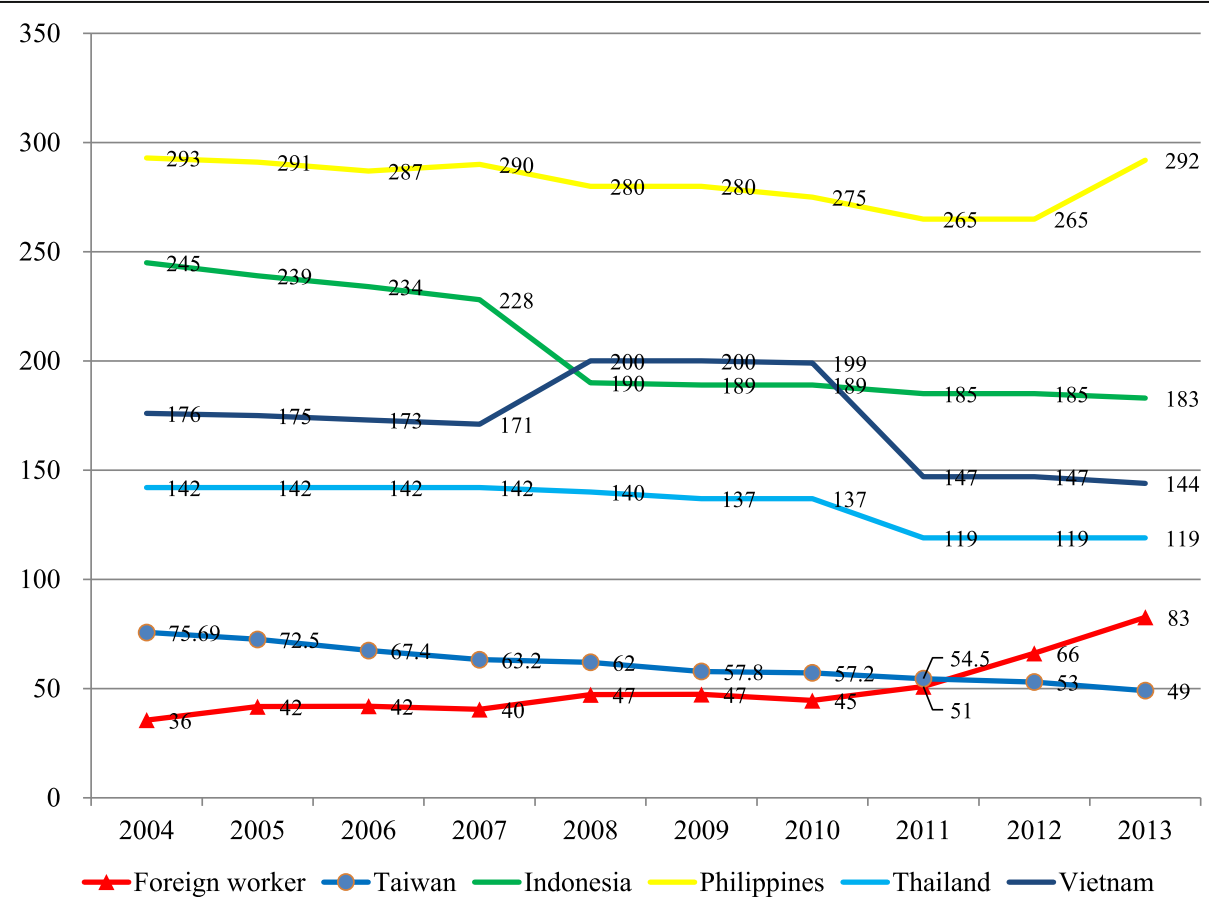

Fig. 2 Tuberculosis incidence (persons per 105) among the migrant workers, their native countries and Taiwan 
Table 3 Comparison of TB incidence among foreign laborers and Taiwanese, stratified by gender, 2004 to 2013

\begin{tabular}{|c|c|c|c|c|}
\hline & Tuberculosis cases & Average incidence $^{a}$ & Hazard ratio & $P$ value \\
\hline \multicolumn{5}{|l|}{ All } \\
\hline Taiwan & 140384 & 61.1 & 1.00 & \\
\hline All migrant workers & 2255 & 58.4 & $0.97(0.93-1.01)$ & 0.1846 \\
\hline Indonesia & 786 & 60.1 & $1.00(0.93-1.07)$ & 0.9173 \\
\hline Philippines & 606 & 76.4 & $1.22(1.15-1.30)$ & $<.0001$ \\
\hline Thailand & 514 & 61.2 & $0.98(0.89-1.07)$ & 0.6003 \\
\hline Vietnam & 348 & 39.8 & $0.57(0.47-0.68)$ & $<.0001$ \\
\hline \multicolumn{5}{|l|}{ Male } \\
\hline Taiwan & 95777 & 82.4 & 1.00 & \\
\hline All migrant workers & 963 & 65 & $0.76(0.70-0.83)$ & $<.0001$ \\
\hline Indonesia & 180 & 98.8 & $1.18(1.03-1.33)$ & 0.0152 \\
\hline Philippines & 199 & 69.6 & $0.83(0.69-0.97)$ & 0.0170 \\
\hline Thailand & 407 & 61.8 & $0.71(0.61-0.81)$ & $<.0001$ \\
\hline Vietnam & 176 & 49.7 & $0.50(0.35-0.64)$ & $<.0001$ \\
\hline \multicolumn{5}{|l|}{ Female } \\
\hline Taiwan & 42643 & 37.3 & 1.00 & \\
\hline All migrant workers & 1292 & 55.9 & $1.40(1.35-1.46)$ & $<.0001$ \\
\hline Indonesia & 606 & 55.2 & $1.39(1.31-1.47)$ & $<.0001$ \\
\hline Philippines & 407 & 71.9 & $1.66(1.56-1.75)$ & $<.0001$ \\
\hline Thailand & 107 & 83.4 & $1.80(1.62-1.99)$ & $<.0001$ \\
\hline Vietnam & 172 & 33.1 & $0.88(0.73-1.03)$ & 0.1145 \\
\hline
\end{tabular}

${ }^{a}$ Average Incidence was represented with annual cases per $10^{5}$ persons in 10 years average Poisson regression model was applied to test the differences among each group

workers [27]. Most of the household workers and health care workers were young and female which frequently contacted with the elderly and the persons with chronic illness which were groups with high proportion of tuberculosis infection. In line with previous systematic review and meta-analysis, there is a higher burden of LTBI among health care workers than general population in high burden countries [28]. Also, the matched cohort study in Taiwan revealed that the health care workers were in an increased risk of active TB compared with general population [29]. Besides, in previous studies in US and China, a proportion of migrant workers lived in

Table 4 Comparison of TB incidence among migrant workers and Taiwanese, stratified by age group, 2004 to 2013

\begin{tabular}{|c|c|c|c|c|}
\hline & Tuberculosis Cases & Incidence $^{a}$ & Hazard ratio & $P$ value \\
\hline \multicolumn{5}{|l|}{$\leq 24$ year-old } \\
\hline Taiwanese & 8862 & 12.4 & 1.00 & \\
\hline Migrant workers & 457 & 65.9 & $5.30(4.83-5.83)$ & $<.0001$ \\
\hline \multicolumn{5}{|l|}{ 25-34 year-old } \\
\hline Taiwanese & 9631 & 25.2 & 1.00 & \\
\hline Migrant workers & 1367 & 66.4 & $2.63(2.49-2.79)$ & $<.0001$ \\
\hline \multicolumn{5}{|l|}{ 35-44 year-old } \\
\hline Taiwanese & 12,203 & 32.7 & 1.00 & \\
\hline Migrant workers & 427 & 45.7 & $1.40(1.27-1.54)$ & $<.0001$ \\
\hline \multicolumn{5}{|l|}{ 45-54 year-old } \\
\hline Taiwanese & 17,930 & 49.6 & 1.00 & \\
\hline Migrant workers & 32 & 30.8 & $0.62(0.44-0.88)$ & 0.0071 \\
\hline
\end{tabular}

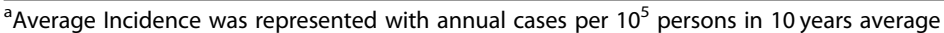
Poisson regression model was applied to test the differences among each group 
crowded and poor surroundings [30,31] which might increase the ongoing transmission of TB from cases of reactivation of LTBI to TB naive persons nearby among migrant workers. Furthermore, migrant workers experienced more stress during their daily work [32] and was less accessible to medical services which make them more vulnerable to infectious diseases. Because we did not performed polymerase chain reaction and bacterial cultures in each case, the active TB of young female migrant workers could be resulted from LTBI or a new infection after close contacts of persons with tuberculosis [21]. No matter the high TB incidence of the migrant workers were from LTBI or a new infection, they were all active in social community and easily spread the Mycobacterium tuberculosis to the public. Because the migrant workers are accounted for approximately $2 \%$ of total population in Taiwan, it is important to review the current screening program of migrant workers to improve TB control.

In Taiwan, once the migrant workers were diagnosed with new active TB, they have to receive 14-days treatments and repatriate back to their native countries [12]. Also, the migrant workers with active TB would be suspended from their work and quickly process the repatriation. Since cultured-based laboratory results require 6-weeks to final report, the migrant workers have relatively low culture data [27]. Nevertheless, chest X-ray is a valid and cost-saving screening tool for active and old healed TB, and is widely used in countries with migrant workers from high-burden areas [33]. The problem is that chest X-ray for active TB screening poses an unneglectable risk of onward reactivation of LTBI when migrant workers come from high TB risk countries [7]. Therefore, adding a screening tool of LTBI for high risk group in migrant workers is one of the applicable approaches in the future.

There are several limitation in our study. First of all, this was a retrospective cohort study and subjects' information was obtained from the registration of local health administrations. Although we extracted several important confounding factors including origin countries, age and genders of migrant workers, the impact of unobserved and unmeasurable confounding factors such as histories of close contact with TB and underlying diseases of migrant workers cannot be ruled out. Second, the TB diagnosis in this study was based on either culture positive or radiological manifestation which might be not reflect the true tuberculosis infection. And, the proportion of positive TB smear or culture among reported active TB in migrant workers was only one third in Taiwan [27]. Besides, the tuberculosis cases of Taiwanese population were not detected by active screening which might cause an underestimation in the TB incidence in Taiwan. Furthermore, because all migrant workers were seronegative of HIV before their entry and were excluded from the study once diagnosis of HIV infection, the HRs of TB incidence might be higher than our estimation between the migrant workers and Taiwanese. In Taiwan, HIV is also a notifiable disease by the Law on the Control of Communicable Diseases in Taiwan. The annual reported new cases of HIV in Taiwan were 6.7-9.6/per $10^{5}$. Due to the very low incidence of native HIV in Taiwan, we did not consider the problem of co- occurrence of TB and HIV [34].

However, this nationwide epidemiological investigation was consisted of whole population in Taiwan and all migrant workers from 2004 to 2013 which was representative and might provide a guide for further tuberculosis control in Taiwan.

\section{Conclusions}

In conclusion, we demonstrated that the female and young migrant workers from high TB incidence countries were as a key reservoir of tuberculosis with consequently reactivation of LTBI and a probable risk of ongoing transmission in the first few years after their arrival. Our findings implied that this risky group should be prioritized to screen for LTBI as well as active TB in pre-arrival and post-arrival program. Further investigation and culture-based studies were warranted.

\section{Abbreviations}

Cls: Confidence intervals; HRs: Hazard ratios; LTBI: Latent tuberculosis infection; NHI: National Health Insurance; TB: Tuberculosis

\section{Acknowledgements}

We would like to thank Miss Chia-Chi Yu for her administrative assistance in the study.

\section{Funding}

This study has been partially sponsored by the Centers for Disease Control, Taiwan (YH10635).

Availability of data and materials

Please contact the authorship team to enquire regarding access to material.

\section{Consent to participate}

Not applicable; big data with individual de-identified detail.

\section{Authors' contributions}

CWL was responsible for the data analysis and interpretation, and drafting and editing of the paper. KCH contributed to the study's conception, initiation and design, the interpretation of the results, and editing of the paper. All authors reviewed and approved the final submission.

\section{Ethics approval and consent to participate}

The design of the study was approved by the Research Ethics Committee in National Taiwan University Hospital in Taiwan (201807018W) before the study was conducted.

\section{Consent for publication}

Written informed consent was not obtained from the participant for publication because of the individual de-identified details in original row data.

Competing interests

The authors declare that they have no competing interests. 


\section{Publisher's Note}

Springer Nature remains neutral with regard to jurisdictional claims in published maps and institutional affiliations.

\section{Author details}

'Department of Family Medicine, National Taiwan University Hospital, Taipei, Taiwan. ${ }^{2}$ Department of Family Medicine, College of Medicine, National Taiwan University, Taipei, Taiwan. ${ }^{3}$ Department of Family Medicine, National Taiwan University Hospital Bei-Hu Branch, Taipei, Taiwan. ${ }^{4}$ Centers for Disease Control, Taipei, Taiwan. ${ }^{5}$ Department of Medical Education, National Taiwan University Hospital, Taipei, Taiwan.

Received: 2 October 2018 Accepted: 20 February 2019

Published online: 28 February 2019

\section{References}

1. World Health Organization. Global Tuberculosis Report, 2017.

2. Chiang CY, Enarson DA, Yang SL, Suo J, Lin TP. The impact of national health insurance on the notification of tuberculosis in Taiwan. Int J Tuberc Lung Dis. 2002;6(11):974-9.

3. Cheng TM. Taiwan's new national health insurance program: genesis and experience so far. Health Aff. 2003;22(3):61-76.

4. Lo HY, Yang SL, Chou P, Chuang JH, Chiang CY. Completeness and timeliness of tuberculosis notification in Taiwan. BMC Public Health. 2011;1: 915

5. Center for Disease Control, Department of Health, executive yuan, Taiwan. Tuberculosis annual report, 2017. Available from: https://daily.cdc.gov.tw/ stoptb/CareMagChart.aspx

6. Aldridge RW, Zenner D, White PJ, Muzyamba MC, Loutet M, Dhavan P, et al. Prevalence of and risk factors for active tuberculosis in migrants screened before entry to the UK: a population-based cross-sectional study. Lancet Infect Dis. 2016;16(8):962-70.

7. Aldridge RW, Zenner D, White PJ, Williamson EJ, Muzyamba MC, Dhavan P, et al. Tuberculosis in migrants moving from high-incidence to lowincidence countries: a population-based cohort study of 519,955 migrants screened before entry to England, Wales, and Northern Ireland. Lancet. 2016;388(10059):2510-8.

8. Greenaway C, Sandoe A, Vissandjee B, Kitai I, Gruner D, Wobeser W, et al. Tuberculosis: evidence review for newly arriving immigrants and refugees. CMAJ. 2011;183(12):E939-51.

9. Aldridge RW, Yates TA, Zenner D, White PJ, Abubakar I, Hayward AC. Preentry screening programmes for tuberculosis in migrants to low-incidence countries: a systematic review and meta-analysis. Lancet Infect Dis. 2014; 14(12):1240-9.

10. Tsang CA, Langer AJ, Navin TR, Armstrong LR. Tuberculosis among foreignborn persons diagnosed $\geq 10$ years after arrival in the United States, 20102015. MMWR Morb Mortal Wkly Rep. 2017;66(11):295-8.

11. Walter ND, Painter J, Parker M, Lowenthal P, Flood J, Fu Y, et al. Persistent latent tuberculosis reactivation risk in United States immigrants. Am J Respir Crit Care Med. 2014;189(1):88-95.

12. Bai K, Chiang CY, Lee CN, Chang JH, Wu LC, Yu MC. Tuberculosis among foreign-born persons in Taiwan, 2002-2005. J Formos Med Assoc. 2008; 107(5):389-95.

13. Ministry of the Interior Executive Yuan, Taiwan. Statistical Yearbook of Interior, 2014. Available from: https://www.moi.gov.tw/stat/english/node. aspx?sn=7255

14. The World Bank. Incidence of tuberculosis. Available from: http://data. worldbank.org/indicator/SH.TBS.INCD.

15. Ministry of the Interior, Executive Yuan, Taiwan. Monthly Bulletin of Interio Statistics, 2014. Available from: https://www.moi.gov.tw/files/site_stuff/321/ 1/month/month_en.html

16. Center for Disease Control Department of Health, Executive Yuan, Taiwan. Tuberculosis annual report, 2013. Available from: https://www.cdc.gov.tw/ english/infectionreport.aspx?treeid=3847719104be0678\&nowtreeid= ffb51203f16bfe57

17. Ministry of the Interior Executive Yuan, Taiwan. Bulletin of Interior Statistics, 2014. Available from: https:/www.moi.gov.tw/files/site_stuff/321/2/year/ year_en.html

18. Zumla A, George A, Sharma V, Herbert RH, Oxley A, Oliver M. The WHO 2014 global tuberculosis report--further to go. Lancet Glo Health. 2015;3(1): e10-2.
19. Center for Disease Control Department of Health, Executive Yuan, Taiwan. Taiwan Guideline on TB Diagnosis and Treatment, 2011.

20. Baussano I, Mercadante S, Pareek M, Lalvani A, Bugiani M. High rates of mycobacterium tuberculosis among socially marginalized immigrants in low-incidence area, 1991-2010, Italy. Emerg Infect Dis. 2013;19(9):1437-45.

21. Flood J, Scott J, Belknap R. Latent mycobacterium tuberculosis infection. N Engl J Med. 2015;373(12):1179.

22. O'Garra A, Redford PS, MCNab FW, Bloom Cl, Wilkinson RJ, Berry MP. The immune response in tuberculosis. Annu Rev Immunol. 2013;31:475-527.

23. Cohen T, Murray M. Incident tuberculosis among recent US immigrants and exogenous reinfection. Emerg Infect Dis. 2005;11(5):725-8.

24. Liu Y, Weinberg MS, Ortega LS, Painter JA, Maloney SA. Overseas screening for tuberculosis in U.S.-bound immigrants and refugees. N Engl J Med. 2009; 360(23):2406-15.

25. Posey DL, Naughton MP, Willacy EA, Russell M, Olson CK, Godwin CM, et al. Implementation of new TB screening requirements for U.S.-bound immigrants and refugees - 2007-2014. MMWR Morb Mortal Wkly Rep. 2014; 63(11):234-6.

26. Horton KC, MacPherson P, Houben RM, White RG, Corbett EL. Sex differences in tuberculosis burden and notifications in low- and middleincome countries: a systematic review and meta-analysis. PLoS Med. 2016; 13(9):e1002119.

27. Lin SY, Wei SH, Tsai SH, Chang CW, Huang WT, Chen LH, et al. Review of repatriation measures for foreign laborers with pulmonary tuberculosis in Central Taiwan. Epidemiol Bull. 2013;29(8):79-87.

28. Nasreen S, Shokoohi M, Malvankar-Mehta MS. Prevalence of latent tuberculosis among health care workers in high burden countries: a systematic review and meta-analysis. PLoS One. 2016;1 1(10):e0164034.

29. Pan SC, Chen YC, Wang JY, Sheng WH, Lin HH, Fang $C T$, et al. Tuberculosis in healthcare workers: a matched cohort study in Taiwan. PLoS One. 2015; 10(12):e0145047.

30. Ziebarth A. Housing seasonal Workers for the Minnesota Processed Vegetable Industry. Rural Sociol. 2006;71(2):335-57.

31. Zheng S, Long F, Fan CC, Gu Y. Urban villages in China: a 2008 survey of migrant settlements in Beiijing. Eurasian Geogr Econ. 2009:50(4):425-46.

32. Hovey JD, Magana CG. Exploring the mental health of Mexican migrant farm workers in the Midwest: psychosocial predictors of psychological distress and suggestions for prevention and treatment. J Psychol. 2002;136: 493-513.

33. Pareek M, Greenaway C, Noori T, Munoz J, Zenner D. The impact of migration on tuberculosis epidemiology and control in high-income countries: a review. BMC Med. 2016;14:48.

34. Center for Disease Control, Department of Health, Executive Yuan, Taiwan. Data avalaible from: https://www.cdc.gov.tw/professional/list.aspx?treeid= 3f2310b85436188d\&nowtreeid=2285b9745a0a3cbb

Ready to submit your research? Choose BMC and benefit from:

- fast, convenient online submission

- thorough peer review by experienced researchers in your field

- rapid publication on acceptance

- support for research data, including large and complex data types

- gold Open Access which fosters wider collaboration and increased citations

- maximum visibility for your research: over $100 \mathrm{M}$ website views per year

At BMC, research is always in progress.

Learn more biomedcentral.com/submissions 